\title{
Sociocultural Perspectives on Foreign Language Learning
}

\author{
Mansoor Fahim \\ Allameh Tabataba'i University, Tehran, Iran \\ Email: dr.mfahim@yahoo.com \\ Mastaneh Haghani \\ Islamic Azad University, Science and Research Campus, Tehran, Iran \\ Email: mst.haghani@gmail.com
}

\begin{abstract}
This paper aims at presenting a brief overview of the major theoretical claims of the sociocultural theory (SCT) of mind and mental development with particular attention to how it relates to the learning and teaching of second/foreign languages. The sociocultural perspective has profound implications for teaching, schooling, and education. The main idea of this psychological view of human development is that social interaction is responsible for the development of higher order functions. In this regard it is believed that just the individual's internal cognitive process cannot account for developmental process. The researchers should also consider the external social factors in the child's environment. Children participate in activities which entail the use of cognitive and communicative functions and by doing so, these functions scaffold and nurture them in their developmental process. Hence in language classrooms successful instructions should be within the child's zone of proximal development (ZPD) and also successful learning process cannot be an individual's unmediated or unassisted effort but a collaborative process.
\end{abstract}

Index Terms-Sociocultural Theory, social interaction, internal cognitive process, external social factors, Zone of Proximal Development, collaborative process

\section{INTRODUCTION}

Vygotsky's sociocultural theory (SCT) has had an immense impact on the field of education. Although he does not deny the indispensable roles of biological factors in elementary processes to emerge, he maintains that sociocultural factors are also significant in the development of the human being's mental processes. Vygotsky (1978) regards sociocultural settings as the essential and determining factor in the development of higher mental activities including voluntary attention, intentional memory, logical thought, planning and problem solving. In sociocultural theory learning is thought of as a social event taking place as a result of interaction between the learner and the environment. Sociocultural theory has its origins in the writings of the Russian Psychologist L.S. Vygotsky and his colleagues. SCT considers human mental functioning as essentially a mediated process organized by cultural artifacts, activities and concepts (Lantolf, 2000). According to this view, the existing cultural artifacts enable human beings to regulate and modify his behavioral and biological activities. Language is also believed to be the primary means of mediation. Developmental processes occur as the outcome of child's participation in cultural, linguistic and historical settings such as getting involved in interactions within families, peer groups, educational institutions, workplaces, sport activities, etc. Although Vygotsky does not reject the neurobiological factors for higher level of thinking ability, he stresses on the importance of interactions within social contexts in the development of human's cognitive ability (Lantolf and Thorne, 2007).

\section{THE THEORY AND ITS CONSTRUCT}

Vygotsky's SCT was concerned with the crisis of the $20^{\text {th }}$ century regarding the challenge between two main camps of psychologists -those who were advertising a naturalistic perspective (the behaviorists) and those who followed a humanistic approach in psychology and emphasized the description and understanding of mental activities. The followers of a naturalistic approach focused on the naturalistic endowments, the biological endowments that humans share with primates, which were largely involuntary and reflexive in the presence of stimuli. Vygotsky's concern was mainly focused on higher mental thinking, rational thought, problem-solving, planning, meaning- making, etc. Vygotsky proposed that human beings possess two different levels of biological foundations. One was lower-level activities and the higher-level abilities, which include consciousness. He stated that by employing higher level cultural tools, such as language, literacy, numeracy, logic, etc., humans are able to have voluntary control over his/her consciousness. The role of these tools is to act as a buffer between an individual and the environment and mediate between the person and his/her social/physical world (Lantolf and Thorne, 2007). 
Sociocultural theory has a holistic approach towards learning. The theory emphasizes meaning as the central aspect of any teaching and holds that skills or knowledge must be taught in all its complex forms, rather than presented as isolated, discrete concepts (Turuk, 2008). Learners are thought to be active meaning-makers and problem-solvers in their learning process. The theory also lays great stress on the dynamic nature of interconnections among teachers, learners and tasks and advocates concept of learning which stems from interactions among individuals.

Ellis (2000) argues that sociocultural theory is based on the assumption that learning emerges not through interaction but in interaction. When learners get involved in doing certain tasks with the help of another learner or the teacher, they internalize the way to carry out the same task by themselves. Hence, social interaction is believed to facilitate or mediate the learning process. According to Ellis (2000) the interactions that help the learners with their learning process are those in which the learners scaffold the new tasks.

One of the key contributions of sociocultural theory to the issue of language learning is that of 'participation' (Pavlenko and Lantolf, 2000, cited in Davies, 2007) which combines the social context with individual acquisition. In other words, In order for an individual to become a competent speaker of a language, the mere personal effort would not result in the mastery of the language unless he benefits from other people's (especially adult) participation to negotiate through the Zone of Proximal Development(ZPD).

\section{A. Zone of Proximal Development}

The concept of ZPD in sociocultural theory is expanded far beyond the original form of it which was introduced by Vygotsky (Cook, 2008). The dissatisfaction with two practical issues in educational psychology prompted Vygotsky to introduce the concept of ZPD. These issues included the assessment of a child's intellectual abilities and the evaluation of instructional practices (Turuk, 2008). Regarding the first issue, Vygotsky argues that the testing techniques used only assessed the actual level of development, yet ignored the potential abilities of the child. He maintained that psychology should be more concerned with the potential abilities of a child, i.e. what a child will be to accomplish in the future but he/she has not achieved yet. In order to predict the future abilities of children and the importance of it, he defined the concept of ZPD as "the distance between a child's actual developmental level as determined by independent problem solving and the higher level of potential development as determined through problem solving under adult guidance or in collaboration with more capable peers" (Turuk, 2008, pp. 248-249).

ZPD contributes to shaping the mental functions of a child which has not become mature yet, but will develop in future. According to Cook (2008) the distinctive aspect of Vygotsky's ZPD lies in the fact that "the gap between the learner's current state and their future knowledge is bridged by assistance from others; learning demands social interaction so that the learner can internalize knowledge out of external action"(p. 229). ZPD is considered significant in the sense that it is the region in which the transition from interpsychological functions (between people) turns into intrapsychological functions (inside the child). It is believed that learning causes a variety of internal developmental functions to be activated and this process happens only when the child is interacting with his peers or the adults in his environment. When the internalization of the learning process occurs for the child, it becomes part of his/ her internal achievements. Vygotsky contends that instruction is not the only determining factor, the biological factors also play an important role in ZPD. These two processes are intertwined in such a complicated way that one cannot consider a distinct role for either instruction or development per se. Vygotsky maintains that the child's development and intellectual possibilities determine the boundaries of the child's possible development.

Shayer (2002, cited in Turuk 2008) suggests that

...good instruction should proceed ahead of development and should awaken and rouse to life an entire set of functions, which are in the stage of maturation and lie in the ZPD. It is in this way that instruction can play an extremely important role in development (p.249).

A major pedagogical implications of ZPD is its emphasis on the collaboration and social interaction. Newman, Gleitman, and Cole (1989, cited in Lantolf \& Thorne, 2006) name dialogic interaction and social mediation as the necessary elements for learning and development to occur. They maintain that cognition change does not take place if the system is a closed one and it is because of the constructive process of the zone that production change is possible. After Bruner's introduction of scaffolding (1986), Donato(1994) extends the notion by suggesting that scaffolding is a framework for peer interaction and individuals can scaffold one another. He maintains that the dialogic interaction has potential to foster linguistic knowledge. Some examples of peer scaffolding can be dyadic interactions between students such as role-plays, translations and interview tasks. The notion of the ZPD also suggests that teachers, both in practice and in training, can achieve an insight to teaching through reflective practice and collaboration with other teachers. Furthermore, an enlarged notion of the ZPD implies that mediation is not limited to the scaffolding offered by other human beings but may come in the form of socially constructed semiotic artifacts, such as books, maps, and diagrams.

\section{B. Internalization}

Another sociocultural theory concept is the notion of internalization, that is, the process by which intermental functioning in the form of social relations among individuals and interaction with socially constructed artifacts is turned inwards and transformed into intramental functioning (Vygotsky,1978). A pedagogical implication of internalization for second/foreign language classrooms is the enhancement of interactions among the learners. Following the significance of interaction among the learners, it is also vital that teachers realize that the role of expert is not limited to 
that of a teacher, but it can also be applied to those learners who have internalized an aspect of the language. To have the experts help the less able learners, reciprocal teaching can be adopted, where the expert learner takes on the teacher's role within a group. However, the concept of internalization raises another issue.

Over the years of studying at schools, there are various concepts that have been internalized for them. These issues include the role of the teachers, the roles of the learners, how classes should be handled and how instruction should take place. Therefore, it may seem to be hard for them to change their conception regarding the role of the teacher. Thus, when they are asked to have a learner-centered approach in their instruction or incorporate reciprocal teaching, it may conflict with their own internalized notions of the roles of teacher and student.

\section{Mediation Theory}

One of the most important aspects of sociocultural theory is the concept of mediation. As human beings use physical tools to make changes in their environment, and consequently upgrade the conditions of their lives, they also use symbolic tools, or signs, to mediate and regulate their relationships with the people in their surroundings and thus change the nature of their relations with them. Williams and Burden (1997) point out that

For Vygotsky and his followers, mediation refers to the use of 'tools'. Tools in this sense refer to anything that is used in order to help solve a problem or achieve a goal. The most important of these tools is symbolic language..., the use of meditational language to help learners move into and through their Zone of Proximal Development(ZPD) is of particular significance. (p. 65)

An example clarifying the psychological mediation is the effectiveness of the use of a tool, such as a shovel or a backhoe to dig a hole in the ground in comparison with the use of bare hands without the use of a tool for the same purpose. Because the above mentioned tools (a backhoe or a shovel) are culturally constructed, they give more power to the human beings to act more effectively and make changes in their lives. Likewise, we use symbolic artifacts to establish an indirect or mediated relationship with the world. Lantolf (2000) states that in Vygotsky's view the task of a psychologist is to discover how the world of human beings are affected through the use of "culturally constructed artifacts" (p. 4).

Turuk (2008) also elaborates on the issue of mediation, holding that not matter whether the tools are symbolic or not, they are artifacts mad under specific cultural and historical conditions, and as such they possess the characteristics of the culture from which they are originated. Their function is to solve problems that cannot be solved otherwise. In turn, they also have an impact on the individuals who use them in that they cause the previously unknown activities and previously unknown ways of conceptualizing phenomena in the world to emerge. Thus, they undergo changes and modifications as they are passed on from one generation to the next, and each generation reshape them to suit the purposes and aspirations of each community.

Sociocultural theory rejects the view regarding the unified nature of thinking and speaking. It also does not accept the communicative view of language which suggests that thinking and speaking are totally independent phenomena and that speaking acts as a transmitter of already shaped thoughts. Sociocultural theory suggests that thinking and speaking as independent units are closely connected. Lantolf (2000) holds that "while separate, thinking and speaking are tightly interrelated in a dialectic unity in which publicly derived speech completes privately initiated thought"(p.7). Therefore, one cannot explain thought without its relation with language and how it manifests itself through it and linguistic activities cannot be accounted for without considering what the related thought is. Vygotsky (1978) holds that

"Thought and speech are two intersecting circles. In their overlapping parts, thought and speech coincide to produce what is called verbal thought. Verbal thought does not include all forms of thought. There is a vast area of thought that has no direct relation to speech. The thinking manifested in the use of tools belongs in this area. As does practical intellect in general"'(p. 87).

\section{Activity Theory}

Activity theory, as one of the components of SCT, was developed by one of Vygotsky's student, A. Leontev. It deals with the unified nature of human behavior, which is considered to be the result of the integration of social and cultural mediations. Lauria (1979) believes that mind is not the result of the activity occurring in the brain but a functional system shaped as the brain's electro-chemical processes come under control of our cultural artifacts, the most important of which is language. In line with Luria (1979), Lantolf (2000) also suggests that an activity is motivated by a need which might be either social, like the need to get literate or biological, such as the need for food, which is hunger. Therefore, it is believed that motives emerge through certain activities which are goal directed and are accomplished under certain conditions.

To explore the implications of activity theory for second/foreign language acquisitions, and to find out how activity theory brings new insights for language development, several studies have been conducted (Such as, Gillette, 1994; Parks, 2000). Coghlan and Duff (1994, cited in Wen, 2008) examined a task-based performance from the activity theory perspective. They contended that scholars always view tasks as being scientifically controllable and measurable, yet they expressed their doubt about the constant nature of a task and argued that tasks are quite variable. They contended that different people react differently to the same task. They proposed an active role for the learners and maintained that learners are active agents who, according to their own objectives, give specific directions to the activities and even different times and conditions have different impacts on their performance on the same task. "The activity becomes 
unique for each learner because it emerges from the interaction between the speakers and the interviewer, the setting, the subjects' motivations and histories. Therefore, it cannot be separated from its sociocultural context, from which it is co-constructed" (Wen, 2008, p.20).

Gillette (1994) also probed into the issue of individual differences through a series of in-depth case studies in the activity of language acquisition and proposed that the learning outcome is closely linked to the learners' motives and that their motives are socially and historically constructed, for example some learners wish to acquire a second language as much as possible while others may acquire it just to meet certain purposes. She also highlighted the fact that the use value they ascribe to language arises from the contact with the world, for example while efficient learners travel a lot, less efficient learners may not. In other words, she attributed the degree of success in the language learning process to the learners' motive, his/her goal and value, which are socially and historically constructed. In line with Gillette (1994), Wen (2008) also views language learning through the lens of activity theory and believes that choosing certain tasks for language teaching is under the influence of the learners' motives, goals and condition of learning. He argues that "while task-based language learning and teaching could yield positive learning outcomes, there can be no guarantees, because what ultimately matters is how individual learners decided to engage with the task as an activity" (p. 22).

\section{E. Scaffolding and ZPD}

Scaffolding has been interpreted as social assistance, which is an idea offered mostly by Jerome Bruner (1986). He noticed that children acquire their first language while their parents offer scaffolding in the form of continuous help to them through conversational "formats".

Using Vygotsky's sociocultural theory of mind, Lantolf (2007) elaborates on the nature of collaborative interaction. Learners "scaffold" one another as they take part in collaborative activity and such collaboration would lead to the co-construction of linguistic knowledge. The concept of scaffolding suggests that the knowledgeable person (adult, teacher, or peer) help the less knowledgeable (child, or student) to accomplish a task which he or she would not otherwise be able to do by himself or herself. It is also interpreted as anything a learner benefits from or consults with, which might be a dictionary, grammar books, the traditional classroom technique of Initiation, Response, and Follow up ( IRF), or any corrective feedback offered by the teacher. Scaffolding has also been connected to Vygotsky's ZPD. The ZPD is defined as " the distance between the actual developmental level as determined by independent problem-solving and the level of potential problem-solving abilities as determined through problem solving under adult guidance or in cooperation with more capable peers"(Vygotsky 1978, p. 86). The fundamental idea is that for scaffolding to facilitate L2 learning, it needs to exist within a learner's ZPD. Cook (2008) finds it parallel to the teachability concept stating that "you cannot teach things that are currently out of the learner's reach" (p. 229). Teachability concept suggests that one cannot teach things which are beyond the learners' present level of knowledge.

Aljaafreh and Lantolf (1994) conducted a study which explored the effect of corrective feedback within the ZPD on L2 learning. The result of the study revealed that corrective feedback should not be constant but rather be modified over time so that the learners can take the responsibility for their own learning. Furthermore, Nassaji and Swain (2000) in a follow-up study of Aljaafreh and Lantolf (1994), confirmed that corrective feedback provided within the learner's ZPD is more effective than the corrective feedback offered to the learners regardless of their ZPD. Brown (2007)also likens Krashen's Input Hypothesis to Vygotsky's ZPD, yet he believes that the ZPD is arisen from a social interactionist perspective laying stress on the role of others to help the learners acquire what they cannot do by themselves.

Cook (2008) asserts that the gap between the learners' present level of knowledge and what he/she is going to learn is removed by the assistance offered by the experts. He holds "learning demands social interaction so that the learner can internalize knowledge out of external action"(p.229).

In her study of scaffolding in learner-learner pairs, Storch (2002) studied who dyadic interaction worked between 10 pairs of adult ESL students taking part in three different joint writing tasks. In her study, she distinguished the interactions in terms of "mutuality" (i.e., level of engagement with each other's contribution) and "equality" (i.e., the degree of control or authority over the task). According to her analysis of the interactions, four patterns of dyadic interaction were distinguished: (1) collaborative; (2) dominant-dominant; (3) dominant-passive; and (4) expert-novice. In collaborative dyads, both mutuality and equality were high. That is, there were the elements of willingness and cooperation in their pair work. In dominant-dominant dyads, equality was high but mutuality was low. Both participants contributed to the task equally, yet they were unwilling or unable to fully engage with each other's contribution. In dominant-passive dyads, both mutuality and equality were relatively low. That is, one of the participants was dominant while the other had a passive role. In expert-novice dyads, equality was low or moderate but mutuality was moderate or high. That is, the more knowledgeable acted as an expert, having an encouraging role for the less knowledgeable (a novice) in the collaborative activity. Furthermore, Storch (2002) had a comparison between the results of the pair work and subsequent individual work on each task. She found more instances of transfer of L2 knowledge from pair work to subsequent individual work among the collaborative pair and the expert-novice pair than the other two pairs.

\section{F. Inner Speech}

Vygotsky (1986) perceives language development as a process which begins through social contact with others and then gradually moves inwards through a series of transitional stages towards the development of inner speech. In other words, the phenomenon of inner speech is rooted in the society, as internalized social speech. The importance of inner 
speech can be realized in some psychologists' viewpoints when they describe thought as the inhibited, soundless speech (Vygotsky, 1978).

Vygotsky argues the driving force behind speech is communication among both adults and children. In its earliest stages in children, speech is believed to be a social phenomenon which has a singular purpose (communication) and is multifunctional. However, later, it turns into egocentric speech and communicative speech. Based on the results of a series of experiments on the egocentric speech of children conducted by Vygotsky, Lauria, Leontiev and Levina (1929, cited in Ehrich 2006), it was revealed that egocentric speech was a function directly related to thought and problem solving. Egocentric speech takes place at the time of the child's transfer of social behaviour patterns to his or her “...sphere of inner-personal psychic functions" (Vygotsky, 1986, p.35). Hence, the children's thinking is aloud. In fact, when they think, they utilize the social aspect of speech. Vygotsky (1986) suggests that the egocentric speech becomes inner speech and finally disappears at the age of seven or eight.

Inner speech arises in a developmental fashion: first there is social speech, then comes the egocentric speech of children and finally inner speech is formed. Vygotsky (1986) states, “...inner speech is speech for oneself: external speech is for others" (p. 225).

Private speech is a vital construct with regard to the role of interaction in L2 acquisition. Vygotskyian sociocultural theory suggests that learners initially use language for communicative interaction purposes with their interlocutors and, eventually, this interpersonal speech takes on an intrapersonal function in which the speech is directed to the self. Interpersonal (social) speech can have an intrapersonal (private) function (Lantolf, 2007).

\section{SOCIOCULTURAL APPROACHES TO TASKS}

A range of researchers have explored the significance of interaction itself for the collaborative building of meanings, i.e. the focus is not on the individual within interaction but on the joint interaction that develops as learners co-construct meanings (Gillette, 1994; Lantolf, 2000). These researchers seek to find out how tasks are reinterpreted by learners, maintaining that it is unrealistic to expect tasks to have predictable and dependable qualities (Gillette 1994; Coughlan and Duff, 1994, cited in Wen, 2008). Wen (2008) argues that in any given classroom setting, although all of the participants display the same or similar overt behaviors in a task, the activities might change from one moment to the next, this might be due to the fact that learners normally seek different goals in their language learning process (Lantolf, 2000).

In a study Van Lier and Matsuo (2000, cited in Skehan, 2007) seek to find an effective way of measuring the interaction when learners learn how to interact symmetrically rather than dominate. By using a sociocultural framework to explore the nature of different tasks, Nakahama et al. (2001, cited in Skehan, 2007) advocate the use of discussion tasks for they provide more learning opportunities than do the information exchange task. Finally, Swain and Lapkin (2001, cited in Skehan, 2007) explore how construction of meaning, in the case of dictogloss and jigsaw tasks, offer scaffolding to the learners so that they can collaboratively, notice aspects of the target language grammar only through the collaborative work.

\section{Instruction, DEVElopmEnt, ASSESSMENT, AND THE ZPD}

Vygotsky (1978) in his sociocultural theory considered human beings as social beings whose formation as humans depends necessarily and dialectically on joint social activity, as well as on careful empirical observation of the link between IQ and schooling. Vygotsky had observed that children entering school with low IQs, in comparison with those having a high IQ, generally had a significant increase in their scores as a result of instruction, while children that entered the same institution with high IQs usually did not show a remarkable progress. This led Vygotsky to develop the metaphor of the ZPD in order to account for what he observed in the school setting. An important implication of all this, particularly with regard to language pedagogy, is that instruction, learning, development, and assessment are inseparably interwoven. Vygotsky they did not assume classroom activities as discrete ones as in standard classroom practice, but viewed them as the same activity. To Vygotsky, it is not enough to know what an individual can do alone without assistance, as reflected in traditional approaches to testing: it is necessary to discover what the person can do through scaffolding (i.e., instruction), because it portrays what the person will eventually be able to do when that help has been internalized.

Two individuals, who score the same on a traditional test without overt assistance, may well perform completely differently when assistance is offered. One person may be able to do much more with help, while the other may not. That is why Vygotsky laid emphasis on a kind of instruction which was aimed at the future, at what the person cannot yet do. Recently, the new type of assessment instrument, dynamic assessment works within the framework of Vygotsky's claim on the dialectic unity of instruction, development, and assessment. Dynamic assessment characterizes a number of distinct approaches that use guided learning for the purpose of determining a learner's potential for change. While the traditional and static procedures are aimed at obtaining the products of assessment, dynamic assessment is concerned with the different ways in which individuals who earned the same score achieved that score. Furthermore, while traditional measures reveal only fully developed abilities, dynamic measures are concerned with how well a learner performs when assistance is offered. In dynamic assessment learners are first assessed based on a traditional 
solo performance measure, which might be an IQ test, a math assessment, or a science test. Then, the assistance, in the form of implicit hints, clues or if necessary explicit instruction is offered to the learners. The assistance is then removed and the learners are reassessed, but not just on the original instrument; rather they are provided with a task that exceeds far beyond the original task so that the internalization of the assistance can be determined. Dynamic assessment suggests that both rate and pathway of development are likely to be different for different individuals. This claim from Vygotsky's standpoint presents a challenge to the current way of thinking about L2 learning - that there is a common route and rate at which acquisition takes place.

\section{CONCLUDING REMARKS}

Learning, in Vygotsky's view (1978), can be defined as what an individual is able to do with assistance of another person or an artifact created by others. Assistance can be offered in the form of direct and explicit instructions, such as those happening in schools or educational institutes; or indirect and implicit instruction, such as those occurring in the case of everyday unreflective activity. On the other hand, development can take place only when that assistance is adopted and internalized, which enables individuals to function independently and apply and extend what they have acquired to broader contexts. The relationship between assistance and self-regulated performance is portrayed in the concept of the ZPD.

Vygotsky's SCT also brings a new perspective to how researchers and teachers understand and promote language learning and teaching. One common belief within the framework of SCT is the notion that learning occurs effectively when students interact with one another in foreign language classrooms, yet SCT should not be viewed as a theory just for learners. The knowledge of SCT can also be useful for teachers to discover and create ways to set up tasks and activities which can allow for facilitation of language learning.

Another area that is especially exciting and relevant for L2 pedagogy is that which deals with the ZPD and dynamic assessment. Unlike the traditional assessment which focuses on the final product of what learners have achieved, dynamic assessment seeks to find out how internalization takes place when the assistance is provided. Hence, it holds that the rate and route of the learning for different individuals might differ.

\section{REFERENCES}

[1] Aljaafre, A. \& J. P. Lantolf.(1994). Negative feedback as regulations and second language learning in the Zone of Proximal Development. The Modern Language Journal 78,465-83.

[2] Brown, D. H. (2007). Principles of language learning and teaching.(5th, edn.). NY: Pearson, Education, Inc.

[3] Bruner, J. (1986). Actual minds, possible worlds. Massachusetts: Harvard University press.

[4] Cook, V.(2008). Second language learning and language teaching (4th, edn.).London: Hodder Education.

[5] Davies, A. (2007). An introduction to applied linguistics: From practice to theory (2nd edn.). Edinburgh: Edinburgh University Press.

[6] Donato, R. (1994). Collective scaffolding in second language learning. In: J. P. Lantolf and G. Appel. (eds.), Vygostskian approaches to second language research. N.J: Ablex Publishing Corporation, 33-56.

[7] Ellis, R. (2000). Task-based research and language pedagogy. Language teaching research 4.3, 193-220.

[8] Ehrich, J. F. (2006). Vygotskian inner speech and the reading process. Australian Journal of Educational \& Developmental Psychology 6, 12-25.

[9] Gillette, B. (1994). The role of learner goals in L2 success: Sociocultural theory and children with special needs. In: J.P. Lantolf \& G. Appel. (eds.), Vygotskian approaches to second language research. Norwood, NJ: Ablex, 195-210.

[10] Lauria, A. R. (1979). The making of mind. A personal account of Soviet psychology. Cambridge, MA: Harvard University Press.

[11] Lantolf, P. J. (ed.). (2000). Sociocultural theory and second language learning. Oxford: OUP.

[12] Lantolf, P. J. (2007). Sociocultural Theory: A unified approach to L2 learning and teaching .In J. Cummins \& C. Davison.(eds.), International handbook of English language teaching. NY: Springer Science +Business Media, LLC, 693-701.

[13] Lantolf, J. P., \& S.L. Thorne. (2006). Sociocultural theory and the genesis of second language development. Oxford: OUP.

[14] Lantolf, P., \&S.L. Thorne. (2007). Sociocultural theory and second language learning. In B.Van Patten \& J. Williams.(eds.),Theories in second language acquisition: An introduction. N.J: Lawrence Erlbaum Associates, Inc, 693-701.

[15] Nassaji, H.,\& M. Swain. (2000). A Vygotskian perspective on corrective feedback in L2: The effect of random versus negotiated help on the learning of English articles. Language Awareness 9, 34-51.

[16] Parks, S. (2000). Same task, different activities: Issues of investment, identity and use of strategy. TESL Canada Journal 17.2, 64-89.

[17] Skehan, P. (2007). Language instructions through tasks. In J. Cummins \&C. Davison. (eds.), International handbook of English language teaching. Springer Sciences-Business Media, LLC, 289-303.

[18] Storch, N. (2002). Patterns of interaction in ESL pair work. Language Learning 52.1, 119-155.

[19] Turuk, M. C. (2008). The Relevance and implications of Vygotsky's Sociocultural Theory in the second language classroom. ARECLS 5, 244-262.

[20] Vygotsky, L. S. (1978). Mind in society: The development of higher psychological processes. Massachusetts: Harvard University Press.

[21] Wen, W. (2008). Activity theory and second language acquisition. Sino-US English Teaching 5.5, 19-23. Available at: http://www.linguist.org.cn/doc/su200805/su20080504.pdf. ( accessed 24/6/2011). 
[22] Williams, M.,\& R. L. Burden. (1997). Psychology for language teacher: A social constructivist approach. Cambridge: Cambridge University Press.

Mansoor Fahim, associate professor of TEFL at Allameh Tabataba'I University, Tehran, Iran from 1981 to 2008. At present, he runs Research methods, psycholinguistics, Applied Linguistics, Second Language Acquisition, and seminar classes at M.A. level. Also, First Language Acquisition, Psycholinguistics, and discourse Analysis at Ph.D. level. He has published several articles and books mostly in the field of TEFL and has translated some books into Persian.

Mastaneh Haghani is a PhD student of TEFL at Islamic Azad University of Science and Research Campus, Tehran, Iran. She is a member of English Translation Faculty at Islamic Azad University of Tehran North Branch, Iran. Her areas of interest are second language acquisition, theories of learning and syllabus design. 